\title{
Silva, João Luiz Máximo da. Cozinha modelo: o impacto do gás e da eletricidade na casa paulistana (1870-1930)
}

Eliane Morelli Abrahão*

São Paulo: Edusp, 2008. 216p.

O fogão a lenha, utensílio obrigatório nas casas até meados da década de 1930, estava presente nas cozinhas e não raras vezes tinha sobre si o grande tacho de cobre a cozer vagarosamente os doces de abóbora, de mamão ou cidra, dentre as muitas iguarias preparadas pelas famílias. Esse cômodo da casa traz à tona nossas lembranças de infância e desvenda nossa memória gustativa repleta de aromas e sabores.

João Luiz Máximo da Silva no livro Cozinha modelo, originário de sua dissertação de mestrado, instiga-nos a pensar sobre os hábitos cotidianos desempenhados pelas senhoras, suas escravas e, posteriormente, suas empregadas no preparo dos alimentos que seriam servidos à família no dia a dia ou em ocasiões especiais. É um livro sobre história da cultura material e revela-nos aspectos interessantes dos impactos trazidos às cozinhas das casas paulistanas pela introdução do gás e da eletricidade. Mostra, também, como as donas de casa aderiram a essas novidades. Mas seu interesse vai além dos artefatos e procura entender a dimensão física, sensorial, "que perpassa todos os domínios do existir humano", segundo as palavras do prefaciador, Ulpiano Bezerra de Menezes.

O autor percorre vasta quantidade de documentos - relatórios de diretoria das empresas concessionárias de gás e eletricidade, relatórios técnicos, notícias de jornal, legislação e normas -, focando três grandes temas: história das empresas concessionárias de energia, tecnologia doméstica e habitação. Silva aborda questões de natureza política, sanitária, econômica, tecnológica, cultural e social, além de temáticas diversas, como a arquitetura e o urbanismo, a administração pública e a legislação, os investimentos estrangeiros, os novos

\footnotetext{
* Doutoranda em História Cultural. Centro de Lógica, Epistemologia e História da Ciência, Universidade Estadual de Campinas (CLE/Unicamp). Rua Sérgio Buarque de Holanda, 251, Barão Geraldo. (Caixa Postal 6133). 13083-970 Campinas - SP - Brasil. eliane@cle.unicamp.br
} 
equipamentos integrados às redes de fornecimento de energia e ainda os serviços técnicos, as relações de gênero e a publicidade.

Ao tratar da introdução das empresas de energia e das inovações proporcionadas pela eletricidade, Silva tece um amplo discurso sobre os avanços tecnológicos e econômicos e resgata todo o processo de instalação e os mecanismos de expansão das duas redes de infraestrutura urbana: o gás e a eletricidade. $\mathrm{O}$ autor relata a atuação da empresa de capital estrangeiro The São Paulo Tramway, Light and Power Company Limited (Light), com concessão pública para a exploração da energia pública e doméstica e do transporte urbano, desde finais do século XIX. Em 1912, essa empresa também passaria a controlar a distribuição do gás ao incorporar a The San Paulo Gás Company.

Silva faz uma abordagem atraente dos avanços proporcionados pela introdução da energia elétrica e do gás à paisagem da cidade de São Paulo, descreve o incremento da indústria e do comércio e sua repercussão no dia a dia dos moradores, sobretudo o impacto do uso do gás pelas famílias paulistanas.

Quanto à urbanização, nesse período a administração pública implantou um novo Código de Postura que disciplinava a abertura de ruas, os alinhamentos das construções etc. Porém, com o crescimento demográfico e econômico vivido por São Paulo, essas medidas públicas não foram seguidas. A demanda por habitação para todas as camadas da população fez crescer a malha urbana consideravelmente. As redes de fornecimento de iluminação e gás não atenderam a todos os novos bairros, percebendo-se então uma segregação espacial na cidade.

Nesse cenário de transformações urbanas as companhias de gás anunciavam seu produto nas revistas femininas com o intuito de conquistar as famílias para as novas tecnologias. Esses anúncios ofereciam 'progresso e civilização' e combatiam a antiga tradição da cozinha brasileira - os fogões a lenha -, impondo a mecanização da área de serviço e colocando como ator principal o fogão a gás, símbolo de cozinha moderna, limpa, ordenada e arejada.

Em busca de seu público consumidor - as donas de casa -, as empresas ofereciam cursos especialmente destinados às cozinheiras, ensinando culinária e o manejo dos fogões. Na década de 1910, as revistas femininas publicavam artigos que orientavam as donas de casa na escolha correta da alimentação e na forma de seu preparo, tendo em vista as facilidades proporcionadas pelas novas tecnologias - fogão a gás, panelas de ágata e de ferro -, todas as vantagens que o novo modelo de cozinha representava.

Contribuíram com os anseios das companhias distribuidoras de gás as questões sanitárias implantadas pelo poder público. Em 1918, o Código Sani- 
tário focalizou a questão da higiene e da salubridade dos cortiços e discutiu explicitamente o papel da cozinha na casa e, mais ainda, de seus principais equipamentos, como o fogão. Pouco depois o Padrão Municipal de 1920 dedicou todo um item à organização da cozinha. Antes espaço da casa desprestigiado porque vinculado aos trabalhos braçais, a cozinha passou a ser o alvo principal das autoridades escudadas pelo saber médico. Este a considerava espaço essencial, que deveria ser agregado ao corpo principal do lar e à lógica imposta pelos ideais de urbanização e consumo.

Essas alterações sanitárias não mudaram a realidade, e, por muitos anos os fogões a lenha conviveram com os fogões a gás, não só pelo hábito e pelo conhecimento empírico adquirido no seu manuseio - acendimento, tempo e formas de cozimento -, mas também pela questão econômica, uma vez que a lenha era muito menos onerosa que o gás.

O aparecimento deste novo equipamento, o fogão, é exaustivamente analisado pelo autor de Cozinha modelo, que aborda a sua evolução, de meados do século XIX até a década de 1930, e também a forma de funcionar desse aparelho doméstico. Silva é minucioso em suas descrições e aponta as diferenças entre os fogões tradicionais e os de ferro fundido - estes também conhecidos como 'econômicos' -, os quais usavam lenha, carvão vegetal ou coque e cujo modo de funcionamento e combustão os diferenciava completamente dos fogões a gás.

Os espaços domésticos mereceram atenção do autor em questões que ultrapassam as alterações arquitetônicas e chegam às diferentes formas de moradias, divididas por ele em quatro categorias - os palacetes, as casas médias (com mais de três cômodos), as casas populares e os cortiços. Suas análises sobre a cozinha recaem não só em sua localização - no caso dos cortiços, por exemplo, ela inexistia ou era improvisada -, mas também em sua preconizada modernização. Substituía-se a imagem da cozinha bandeirista, que sugeria trabalho pesado e sujo, desenvolvido longe das áreas de estar em razão de fumaça, cheiro e fuligem, por um modelo limpo, com novo mobiliário, visando eficiência no trabalho.

As novas relações que se tramam entre o espaço privado e o espaço público por intermédio da cozinha criam uma articulação inédita com o espaço urbano. Nas palavras do autor: "A viabilização e comercialização de uma nova tecnologia, aplicada ao trabalho doméstico e distribuída por meio de redes, trouxe um grau de dependência da casa a novas relações, que extrapolaram os antigos limites desse espaço" (p.94).

A difusão do uso de novas práticas e técnicas domésticas estava fortemen- 
te associada aos novos padrões urbanos de embelezamento e sanitarização. Para isso, era necessário romper com o passado colonial e com tudo o que ele representava. A nova cozinha higiênica exigia a participação efetiva da mulher, com novas formas de organizar o tempo e o espaço doméstico, a racionalização de seu espaço e seu gerenciamento econômico. Silva entende que essa importância' da dona de casa relegou a empregada ao papel de mera executora, cabendo à mulher a administração do lar num sentido mais amplo. Estudos de gênero recentes têm revelado que as mulheres nas primeiras décadas do século XX já controlavam o orçamento e as despesas familiares, e esses estudos apontam para uma tendência ao consumo de novidades tecnológicas que facilitassem os afazeres cotidianos do lar, o que sem dúvida satisfazia os anseios das companhias de gás.

No que tange à cultura material, a descrição dos novos artefatos à disposição das donas de casa foi pouco explorado pelo autor. Para apreender os objetos, as novidades tecnológicas que compunham o arsenal de utensílios existentes nas casas paulistanas, faz-se necessária uma pesquisa aos inventários post mortem do período, uma vez que são fonte documental essencial para esses estudos por seu caráter descritivo. Os inventários registram todos os bens da pessoa falecida e que foram objetos da partilha. Nos autos de avaliação, por exemplo, são discriminados os 'bens móveis' - utensílios domésticos, móveis, objetos de decoração e de trabalho - e os 'bens imóveis', ou 'de raiz' - casas, terrenos e plantações. Os aparelhos introduzidos com o advento da eletricidade - torradeiras, cafeteiras e chaleiras, por exemplo - poderiam ter sido mais bem explorados se o autor não se houvesse detido apenas nos anúncios publicitários e na lista de leilões, porque nessas fontes há apenas a indicação dos objetos disponíveis no mercado.

Com narrativa clara e convidativa, Silva nos estimula a percorrer os caminhos da passagem do fogão a lenha para o fogão a gás. Expõe os sentimentos contraditórios em relação à nova tecnologia - crença em seus poderes curativos e terapêuticos, ao lado do medo de intoxicação - e a ideologia de progresso subjacente à propaganda do gás e da eletricidade para o interior das casas. E, sobretudo, revela como a cozinha foi redesenhada em torno do fogão 'moderno', transformando as relações entre patroas e empregadas e a dinâmica no preparo e na escolha dos alimentos. O autor fornece pistas sobre uma possível ligação entre essa nova cozinha e o desenvolvimento da gastronomia e, de forma pontual, aborda a alteração do cardápio que deveria atender aos novos ritmos urbanos, com refeições rápidas e subordinadas a horários específicos. Algumas deficiências podem ser observadas neste trabalho, relaciona- 
das às próprias escolhas temáticas e das fontes, uma vez que o autor se deteve muito na história das empresas concessionárias e pouco nas transformações dos aparelhos elétricos e no surgimento de novos utensílios domésticos.

Resenha recebida em setembro de 2009. Aprovada em dezembro de 2009. 